\title{
A BIOECONOMIA COMO ALTERNATIVA COMPLEMENTAR AO MODELO DE DESENVOLVIMENTO DO AMAZONAS
}

Bioeconomy as a complementary alternative to the Amazon developmente model

Michele Lins Aracaty e Silva

Marcílio Lima de Oliveira 


\title{
A BIOECONOMIA COMO ALTERNATIVA COMPLEMENTAR AO MODELO DE DESENVOLVIMENTO DO AMAZONAS
}

\author{
Bioeconomy as a complementary alternative to the Amazon development model
}

\author{
Michele Lins Aracaty e Silva \\ Marcílio Lima de Oliveira
}

\author{
Grupo de Trabalho (GT): GT7. Desenvolvimento rural, territorial e regional
}

\begin{abstract}
Resumo: O Amazonas foi protagonista de dois modelos de desenvolvimento regional: a Monocultura da Borracha e a Zona Franca de Manaus (ZFM), este último apontado como concentrador de renda e riqueza e incapaz de atender às necessidades básicas infraestruturais. Assim, temos como objetivo analisar a Bioeconomia como alternativa complementar frente ao atual modelo de desenvolvimento aproveitando as potencialidades regionais e a rica biodiversidade através de Parcerias Público-Privadas. Trata-se de uma revisão de literatura com métodos descritivo e explicativo. Acreditamos que a Bioeconomia deverá seguir a linha de uma política pública industrial (bioindustrialização), alinhando crescimento econômico, preservação ambiental, conhecimento da floresta (economia de conhecimento da natureza), ciência (UFAM, UEA, IFAM, CETAM, Sistema S, entre outros) tecnologia e inovação (startups da floresta) para fomentar um modelo econômico local endógeno que gere emprego e renda para as populações locais, preserve a floresta em pé e contribua para reduzir as vulnerabilidades socioeconômicas regionais.
\end{abstract}

Palavras-chave: Desenvolvimento Regional. Amazonas. Bioeconomia. Sustentabilidade.

\begin{abstract}
Amazonas was the protagonist of two regional development models: the Rubber Monoculture and the Manaus Free Trade Zone (ZFM), the latter appointed as a concentrator of income and wealth and unable to meet basic infrastructure needs. Thus, we aim to analyze Bioeconomics as a complementary alternative to the current development model taking advantage of regional potential and rich biodiversity through Public-Private Partnerships. It is a literature review with descriptive and explanatory methods. We believe that Bioeconomics should follow the line of an industrial public policy (bioindustrialization), aligning economic growth, environmental preservation, knowledge of the forest (economy of knowledge of nature), science (UFAM, UEA, IFAM, CETAM, Sistema S, among others) ) technology and innovation (forest startups) to foster an endogenous local economic model that generates jobs and income for local populations, preserves the standing forest and contributes to reducing regional socioeconomic vulnerabilities.
\end{abstract}

Key words: Regional Development. Amazonas. Bioeconomy. Sustainability. 
IGepec, Toledo, V.25, p.46-65, 2021. Edição Especial:58Congresso da SOBER 


\section{INTRODUÇÃO}

Ao longo do processo de desenvolvimento econômico do Estado do Amazonas dois relevantes modelos de desenvolvimento regional ganharam destaque: A Monocultura da Borracha e a Zona Franca de Manaus (ZFM) com o Polo Industrial. Ambos os modelos contribuíram para a riqueza regional, mas com o passar do tempo suas fragilidades começaram a ser mais evidentes e assim surge a necessidade de se identificar outro modelo que possa atender às expectativas socioeconômicas e ambientais regionais.

O ciclo da Monocultura da Borracha contribuiu para o surgimento e urbanização de cidades e para o crescimento regional estabelecendo um grau de importância incomparável à Amazônia durante a sua vigência. O seu término, foi responsável pela profunda recessão econômica e esvaziamento populacional que durou até a implantação do Modelo Zona Franca de Manaus (ZFM) no auge do período militar (Santos, 1980).

Na década de 6o, instalou-se o Modelo Zona Franca de Manaus (ZFM) com o propósito de integração regional e geração de emprego e renda. Todavia, ao longo de 53 anos de vigência, em que pese alguns avanços pontuais, eles foram anulados pela concentração populacional, de renda e de riqueza, uma vez que, a prosperidade gerada pela riqueza do Polo Industrial de Manaus (PIM) não se estendeu para os demais municípios do Amazonas nem mesmo aos que compõem a Região Metropolitana de Manaus (RMM).

Não podemos ignorar a importância econômica do atual modelo de desenvolvimento regional para o Estado do Amazonas bem como para a Região Norte do Brasil, mas observamos que este apresenta fragilidades e ao longo de sua vigência contribuiu pouco ou quase nada para reduzir as vulnerabilidades socioeconômicas infraestruturais (água tratada, esgotamento sanitário, entre outras) além da necessidade de se buscar alternativas para aumentar a preservação ambiental.

Dada as fragilidades e imperfeições do modelo e o fato deste ser um projeto de desenvolvimento regional exógeno e de não ter como base a valorização das potencialidades e riquezas regionais além de sofrer pressões políticas de caráter nacional e ter prazo de vigência se faz imprescindível buscar um modelo econômico que o complemente e que possa atender aos anseios regionais no que tange à geração de emprego e renda nos municípios do interior, fortaleça a preservação ambiental e reduza as vulnerabilidades regionais. Assim, voltamos nossos estudos apontando a Bioeconomia como proposta.

Salientamos que a discussão acerca da Bioeconomia como proposta complementar ao modelo de desenvolvimento regional do Amazonas tem sido objeto de discussões em eventos regionais, nacionais e internacionais e muito se tem observado e acompanhado a publicação de trabalhos em revistas especializadas, artigos e livros. Porém, são escassas as ações implementadas.

O que sabemos até agora é que para que a Bioeconomia venha a trazer ganhos para a população e gere emprego e renda esta alternativa econômica deve receber investimento oriundos de Parceria Público-Privada e com foco para um modelo de base industrial (bioindustrialização) com uma rígida e bem articulada política de incentivo em cadeia e que possa agregar a infraestrutura (universidades e institutos de pesquisas), e capital humano (cientistas, pesquisadores e empreendedores) já 
disponíveis na região. Trata-se assim, de um modelo endógeno com características regionais e com a agregação de valor baseado na biodiversidade transformando o sistema de produção em direção à sustentabilidade.

Para tanto, temos como objetivo analisar a Bioeconomia como alternativa complementar frente ao atual modelo de desenvolvimento aproveitando as potencialidades regionais e a rica biodiversidade através de Parcerias Público-Privada.

Quando ao percurso metodológico, trata-se de uma pesquisa qualitativa de natureza bibliográfica do tipo descritiva e exploratória que teve como base para a sua construção o uso de material secundário já publicado e disponibilizado através de livros, artigos, revistas científicas e de material disponível na internet que serviram de base para a construção teórica com o objetivo de atender aos objetivos da pesquisa.

Observamos que movimentos ligados à Bioeconomia se alinham para apontar um aproveitamento econômico e racional da biodiversidade, mas para que estas iniciativas, ora pontuais e dissociadas, como as que analisamos aqui neste texto, tais como: a presença de bioprodutos já conhecidos e com elevado potencial para exploração, o surgimento de inúmeras startups da floresta com foco em atividades sustentáveis, um novo olhar para a economia através da economia do conhecimento da natureza e experiências como a implantação de pequenas usinas em comunidades (bioindustrialização) possam sair do papel e se tornarem viáveis é imprescindível a cooperação dos stakeholders bem como o fortalecimento de Parcerias Público-Privada.

Assim, este artigo é composto por: Introdução, Revisão de Literatura, onde apresentamos: Os Modelos de Desenvolvimento Regional do Amazonas: O Ciclo da Borracha e a ZFM; Fragilidades do Modelo ZFM: Legado Social e Ambiental; A Bioeconomia como Proposta de Modelo de Desenvolvimento Regional Endógeno; Bioprodutos Amazônicos e suas Potencialidades; Startups da Floresta e o Impulso para a Bioeconomia; Economia do Conhecimento da Natureza e $O$ Modelo de Bioindustrialização da Amazônia. Em seguida teremos o Percurso Metodológico, Resultados e Conclusões e por fim as Referências utilizadas para a construção deste texto.

\section{2 - REVISÃO DE LITERATURA OS MODELOS DE DESENVOLVIMENTO REGIONAL DO AMAZONAS: O CICLO DA BORRACHA E A ZFM}

Historicamente, o Estado do Amazonas foi palco de dois modelos de desenvolvimento regional: O Ciclo da Borracha e o Modelo Zona Franca de Manaus.

Para Weinstein (2002), a atividade de extração do látex da seringueira já dominava o comércio da região muitas décadas antes do boom econômico. Por isso, havia uma certa corrente de resistência por parte de setores da elite ou classe dominante que tinham a preocupação de que a atividade comercial de coleta ou extração do látex não apresentava condições para construir na Amazônia uma sociedade civilizada.

Ainda para a autora (2002), o sistema de produção que dependia de uma forma de trabalho móvel, sem residência fixa, não se mostrou capaz de introduzir melhoramentos e nem construir uma vida familiar "normal" daquilo que convencionalmente entendemos como uma sociedade estável e próspera. Ademais, o movimento conhecido como Cabanagem (revolta popular dos anos de 1830), ainda se fazia constar na memória do tecido social, e com o qual balizava a busca por alternativas que convergissem para formas de produção adequadas aos valores locais. 
De acordo com Santos (1980), o Ciclo da Borracha (1879-1912 e 1942-1945) constitui uma época importante para a história econômica e social do Brasil. Para ele, o período está relacionado com a extração da matéria-prima - o látex, da seringueira (árvore-da-borracha) bem como a comercialização do seu produto, a borracha. Assim, a atividade extrativa do látex transformou a região amazônica num vultoso centro comercial e provocou um processo de expansão da colonização, atraindo riquezas, mudanças arquitetônicas, culturais e sociais que impulsionaram o desenvolvimento das cidades de Belém, Manaus e em menor proporção Porto Velho e fora responsável pela atração populacional, mão-de-obra oriunda de outros estados da Região Norte, da Região Nordeste bem como da Europa (França e Inglaterra) e dos Estados Unidos.

Para o autor (1980), a operação extrativista da matéria-prima (látex) aliada à Revolução Industrial transformou a região amazônica numa área de atração populacional. Houve deslocamento em massa de mão-de-obra, de empreendedores e de investimento regional, nacional e estrangeiro para a região. Em comum, buscavam se beneficiar dos lucros gerados pela atividade. Acredita-se também que, a atividade de extração da borracha na Amazônia tenha contribuído para financiar inclusive a atividade cafeeira, bem como o início do processo industrial brasileiro.

Ainda para Santos (1980), em contrapartida, a derrocada da economia da borracha produziu estagnação econômica e sérios problemas sociais generalizados em toda a região. A perda do investimento combinado com elevados níveis de desemprego desorganizou as bases produtivas das pequenas, médias e até mesmo das mais dinâmicas cidades como Manaus e Belém. Dessa forma, o processo de declínio apontou um sistema produtivo de monocultura incapaz de promover e manter o desenvolvimento regional, e entre os prováveis fatores para o declínio, destacamos: contrabando das sementes em 1877 (biopirataria), produção em larga escala, produto competitivo, melhor qualidade, produção próxima ao centro consumidor, mão-deobra abundante e barata, redução dos riscos da atividade.

De acordo com dados disponibilizados pela SUFRAMA (2020), nesse ínterim, com o fim do Ciclo da Borracha e a implantação do Modelo Zona Franca de Manaus (ZFM), na década de 1960, o principal componente da receita estadual era oriundo da atividade agropecuária, do extrativismo da juta e de forma muito incipiente da borracha. Este cenário só apresentou mudança em 1957, com a instituição do decretolei n. 3.173 de o6 de junho de 1957. Nele, constava a criação do Porto Livre de Manaus, que após dez anos perdeu efetividade com a criação do Polo Industrial de Manaus (PIM) por meio do decreto-lei 288 de 28 de fevereiro.

Destacaremos os números atualizados acerca do modelo para que assim possamos fazer uma análise dos aspectos mais recentes da sua contribuição para o desenvolvimento regional em vista da sua participação e importância no PIB do Estado do Amazonas. Assim, registra-se um aumento de 11,57\% no faturamento em $2019 \mathrm{em}$ comparação ao mesmo período do ano de 2018, com um total de R $\$ 86,7$ bi, responsável pela geração de 2.029 postos de trabalho (efetivos, temporários e terceirizados) ${ }^{1}$.

\footnotetext{
${ }^{1}$ Disponível em: http://www.suframa.gov. Acesso em: 20 de outubro de 2020.
} 
FRAGILIDADES DO MODELO ZFM: LEGADO SOCIAL E AMBIENTAL

Para Araújo e Paula (2009), apesar dos números, favoráveis, o modelo ZFM assim como qualquer outro modelo de desenvolvimento regional, não é totalmente perfeito e apresenta deficiências ou fragilidades: locação ineficiente de fatores de produção; distorção de mercados e cadeias produtivas; não apresenta condicionalidades e metas e constitui um modelo que gera dependência, e apresenta necessidade urgente de: uma agenda de produtividade e competitividade dada a indústria 4.0, de integração de cadeias produtivas, bem como de ajuste no contexto fiscal e tributário além de redução de subsídios à produção.

Uma das grandes discussões acerca do modelo deve-se à concentração econômica e populacional, tal situação pode ser observada da seguinte forma: Centro Amazonense - Manaus (78,7\% da população e 92,6\% do PIB); Norte Amazonense (3,4\% da população e 1\% do PIB); Sudoeste Amazonense (9,9\% da população e 3,3\% do PIB) e Sul Amazonense (8,1\% da população e 3,1\% do PIB). (IBGE, 2020).

De acordo com os dados do IBGE (2019), Manaus concentra a maior parte da atividade industrial com participação de 78,9\% do PIB do Estado do Amazonas, causando o desequilíbrio regional uma vez que nos demais municípios a economia está alicerçada em setores primários com a exploração de atividade de baixo valor agregado.

Ainda segundo Araújo e Paula (2009), passados 53 anos de sua implantação, pouco se viu acerca dos efeitos esperados para o desenvolvimento regional. $\mathrm{Na}$ verdade, o que se observa é a concentração de renda, pobreza e bolsões primitivos de miséria tanto na periferia da capital como nos municípios do interior, inclusive nos que compõem a Região Metropolitana de Manaus (RMM).

Outro dado relevante, é o elevado percentual da população do Estado do Amazonas que se encontra baixo da linha da pobreza. Sobre isso, de acordo com dados do IBGE (2019), 45,7\% dos amazonenses encontrava-se em situação análoga abaixo da linha de pobreza. O registro, considerado o quarto maior do Brasil, apresentou uma redução de 44 mil pessoas, em comparação com o ano anterior.

A esta realidade acrescentamos os números da vulnerabilidade social: são 564 mil pessoas - 14,4\% da população do Estado (194 mil pessoas em Manaus), pobreza e extrema pobreza. Abastecimento de água, esgotamento sanitário e coleta de lixo: 20,3\% da população do $\mathrm{AM}$ não tem acesso à água potável; 90,6\%, não tem acesso à coleta de esgoto; $88,9 \%$, não tem acesso à coleta do lixo e destinação correta dos resíduos de acordo com o IBGE (2019).

De acordo com Araújo e Paula (2019), em relação ao aspecto ambiental, os estudos que sustentam a hipótese de que a ZFM contribui para a preservação, em geral, trazem a percepção de que o PIM não agride o ambiente local e que as atividades industriais da ZFM não requerem o uso intensivo de recursos naturais (como terra e madeira), ao contrário de outras atividades primárias (extração mineral, madeireira, agropecuária extensiva, que estão associadas à grilagem e à especulação imobiliária), que ocorrem de forma recorrente e constante na Amazônia de forma geral.

Rivas, Mota e Machado (2009), afirmam que o processo de crescimento do Polo foi desvinculado da utilização significativa de recursos naturais existentes, enquanto no Estado do Pará o desenvolvimento se deu através da exploração de recursos naturais. Teixeira (2013), Pereira Junior (2015), Costa e Biderman (2014) e Galinari et al. (2007) também falam sobre os benefícios que o desenvolvimento e a concentração industrial podem trazer à região do Polo Industrial de Manaus, diminuindo a atenção dada às atividades intensivas em recursos naturais. Poucos estudos, contudo, 
procuram analisar empiricamente o efeito da ZFM sobre o desmatamento dentro da Região Amazônica onde está localizada o PIM.

Entre os estudos que contestam a hipótese de que a ZFM contribui para a preservação, Carvalho e Domingues (2016) que dizem que, entre 1960 e 1980, a Amazônia apresentou os índices mais elevados de crescimento urbano do país. Porém, com exploração de recursos naturais de forma desordenada, atividades inadequadas de caráter predatório na maioria das áreas ocupadas, e taxas elevadas de desmatamento para empreendimentos agrícolas e abertura de estradas e projetos de infraestrutura e mineração na região. Por sua vez, Nogueira, Sanson e Pessoa (2007) afirmam que a zona urbana de Manaus passa por um processo de insustentabilidade, agravado pelo crescimento demográfico, expansão urbana e modernização dos espaços interurbanos, gerando práticas ambientais predatórias e danosas ao meio ambiente (HOLLAND et al. 2020).

Segundo Carvalho (2015), na Amazônia Ocidental, os índices de desflorestamento apresentam-se sensivelmente mais inferiores em relação aos registrados na Amazônia Oriental. Há questionamentos quanto à razão para esse fato. Alguns estudos apontam que não há evidências para associar o expressivo percentual de floresta em pé na Amazônia Ocidental com a presença da Zona Franca de Manaus. (MIRANDA, 2013, p. 5).

Para Silva (2015), quanto à perspectiva do desenvolvimento ambiental da Zona Franca de Manaus (ZFM), um recente levantamento, oriundo dos estudos da SUFRAMA, confirmou a imprescindibilidade do Polo Industrial de Manaus para a preservação da cobertura verde da Amazônia. A pesquisa resultou na obra "Impacto Virtuoso do Polo Industrial de Manaus sobre a proteção da Floresta Amazônica", desenvolvida por pesquisadores da Universidade Federal do Amazonas (UFAM), Universidade Federal do Pará (UFPA), do Instituto Piatam e do Instituto de Pesquisa Econômica Aplicada (IPEA). Segundo um de seus pesquisadores e coordenador, José Alberto da Costa (informação verbal), o parque fabril manauara contribuiu para a redução de 70\% do desmatamento no Amazonas entre 2000 a 2006 e, até 1997, em aproximadamente 85\%. Essa contribuição resultou na preservação de $98 \%$ da cobertura vegetal do Estado.

Portanto, denota-se que os incentivos fiscais que compõem o modelo Zona Franca de Manaus não se restringem ao mero crescimento econômico da região, pois a SUFRAMA vem se valendo de parcerias e dos recursos das taxas de serviços administrativos para fomentar e promover pesquisas que aprimorem a tecnologia regional fundada nas potencialidades da floresta, o que responde às críticas de que $o$ modelo seria falho por observar interesses externos e desvinculados dos atributos locais (2015).

Ainda segundo o autor (2015), há inúmeras condicionantes sociais e ambientais a serem observadas pelas indústrias para gozarem dos incentivos fiscais do PIM sem contar a necessidade de atentarem para o princípio da reciprocidade, de modo que um percentual dos seus faturamentos é revertido por meio do pagamento de contribuições, a fundos concernentes à interiorização do desenvolvimento, à realização de pesquisas científicas e tecnológicas e ao turismo. Nesse sentido, a ZFM se apresenta como modelo capaz de desenvolver sustentavelmente a região amazônica ocidental e, consequentemente, o Brasil, afirma o pesquisador.

Para Silva (2015), o Amazonas, assim como os demais estados da Região Norte do país apresentam os piores indicadores do Brasil, de elevada vulnerabilidade social. Temos um modelo ora vigente que se configura já estruturado com elevada dinamização do parque industrial local e do modelo atual; uso do Potencial da 
Biodiversidade, de modo sustentável; desenvolvimento científico, tecnológico com foco na inovação; descentralização econômica e geração de ganhos sociais e ambientais, que atrelado aos novos eixos de oportunidades pode contribuir para alavancar a economia e gerar emprego e renda com a utilização de recursos oriundos da parceria público- privado. Dentre os eixos de oportunidade, destacamos a Bioeconomia.

\section{A BIOECONOMIA COMO PROPOSTA DE MODELO DE DESENVOLVIMENTO REGIONAL ENDÓGENO}

Os conceitos e as definições de Bioeconomia derivam dos estudos do matemático e economista Romeno Nicholas Georgescu-Roegen. A base de sua teoria apontava para uma economia ecologicamente e socialmente sustentável com base nas análises econômicas oriundas da biologia. Em seu entendimento, os recursos naturais tendem a serem degradados quando utilizados na atividade econômica, por isso, defendia uma economia centrada na ecologia (GEORGESCU-ROEGEN, 1971). Há na literatura um certo consenso quanto ao pioneirismo dos estudos de Georgescu-Roegen sobre os atuais conceitos da Bioeconomia. Fato é que, o enfoque predominante está atrelado ao valor criado por novas atividades de negócios oriundas do uso inovador e sustentável dos recursos biológicos.

Em sentido contrário, não há um consenso sobre a definição de Bioeconomia. De todo modo, o termo tem evoluído e varia de acordo com autores, porém, são preservados os elementos convergentes (IPEA, 2017), como suas origens em atividades primárias, enfoque transversal (McCORMICK; KAUTTO, 2013) e ênfase na produção econômica com o emprego de tecnologias de conversão de produtos cada vez mais avançadas.

As definições incorporam tanto os aspectos históricos quanto os mais modernos da Bioeconomia. Tradicionalmente, ela envolvia produção e comercialização de alimentos, produtos florestais bem como têxteis naturais (algodão e lã), cervejas, vinhos, queijos e medicamentos naturais também podem ser considerados resultantes dos primeiros processos biotecnológicos, que, ao serem aprimorados por cientistas, constituem a Bioeconomia moderna (2018, p.07).

Segundo informações da FIESP (2019), a Bioeconomia é uma economia sustentável, que reúne todos os setores da economia que utilizam recursos biológicos (seres vivos). Já para a Organização para Cooperação e Desenvolvimento Econômico (OECD), a Bioeconomia movimenta no mercado mundial com cerca de 2 trilhões de Euros e gera cerca de 22 milhões de empregos.

Para o Ministério de Ciência, Tecnologia, Inovação e Telecomunicação (2018), a Bioeconomia é o resultado de uma revolução inovativa na área das ciências biológicas relacionada à invenção, ao desenvolvimento e ao uso de produtos e processos biológicos nas áreas da biotecnologia industrial, da saúde humana e da produtividade agrícola e pecuária.

No Plano de Ação em Ciência, Tecnologia e Inovação em Bioeconomia (PACTI Bioeconomia), o termo é entendido como o conjunto de atividades econômicas baseadas na utilização sustentável e inovadora de recursos biológicos renováveis (biomassa). (MCTIC, 2018, p.o2).

Para a Comissão Europeia (2012), a Bioeconomia é entendida como: a produção oriunda de recursos biológicos renováveis da terra, água e mar, assim como dos resíduos de processos produtivos de transformação e sua conversão em alimentos, rações, produtos de base biológica e bioenergia, incluindo a agricultura, produção

IGepec, Toledo, V.25, p.46-65, 2021. Edição Especial:58 Congresso da SOBER 
florestal, pesqueira, alimentar e de celulose, assim como segmentos das indústrias químicas, biotecnológicas e de energia. Para tanto, a Bioeconomia envolve três elementos: (i) conhecimentos em biomassa renovável; (ii) biotecnologias; e (iii) integração em todas as aplicações.

Segundo o Instituto Escolhas (2019), o panorama da Bioeconomia na Amazônia bem como as suas oportunidades são: a Amazônia possui $24,5 \%$ da fauna e $11,2 \%$ da flora brasileira, 1/3 das espécies vivas do planeta; mais de 5 milhões de espécies vegetais, das quais apenas 30.000 foram identificadas, com vantagem comparativa no mercado de bioprodutos; expansão da produção mais eficiente, que demanda menor área de terra para a geração de rendimento; sua diversidade pode ser explorada e utilizada pela indústria nacional; principais setores beneficiados: alimentos, bebidas e cosméticos; potencial de expansão: para setores com importância econômica elevada, como têxtil, energia e farmacêutico, que podem explorar elementos ao longo de sua cadeia produtiva.

Ainda para o Instituto (2019), se levarmos em consideração a produção atual de $\mathrm{R} \$ 3,1 \mathrm{bi}$, e a estimativa de crescimento de $10 \%$, aumento produtivo de $\mathrm{R} \$ 9,7 \mathrm{bi}$, aumento da renda salarial de $\mathrm{R} \$ 1,5 \mathrm{bi}$, teremos a geração do equivalente a 50.809 empregos para os próximos 10 anos (diretos, indiretos e induzidos).

Para Joly e Nobre (2020), a "Bioeconomia não é apenas um modelo de forte investimento, que exige retorno econômico rápido, geração de empregos e abertura de empresas, recolhimento de impostos, é sobretudo, a adoção de um sistema de sustentabilidade socioambiental", que valoriza a cultura regional e envolve conhecimento tradicional na participação da cadeia produtiva com a integração do conhecimento tradicional com o desenvolvimento tecnológico possibilitando a qualidade de vida para as populações que usufruirão dessa economia.

Para Queiroz e Bustamante (2020), o conceito emergente de Bioeconomia vem sendo citado com frequência como uma alternativa às formas predatórias de uso do solo na Amazônia, no entanto, é preciso considerar perspectivas históricas e os diferentes contextos socioambientais. Nas palavras dos autores, enquanto um grupo analisa a Bioeconomia como um conjunto amplo de atividades econômicas e sistemas produtivos baseados em recursos biológicos renováveis, outro a veem como uma economia baseada em recursos da sociobiodiversidade e do extrativismo. Outras abordagens enfatizam o aspecto biotecnológico, os insumos químicos e as fontes alternativas de energia, sugerindo sua dissociação com os processos tradicionais de uso da biodiversidade e uma ligação a sistemas de produção de alta intensificação tecnológica, destacam que ainda tem espaço para um consenso que permite que diferentes nações se abriguem em propostas genéricas de "Bioeconomia".

O que deve ficar claro e que é incontestável é o fato de que o Brasil detém enorme potencial de capital natural e a maior biodiversidade do planeta, todavia, necessita construir um novo modelo de desenvolvimento com base na associação das diferentes formas de conhecimento com o uso das tecnologias inovadoras. Neste processo, deve-se enfatizar a conservação e respeito às populações tradicionais, redução do desmatamento e degradação ambiental. Evitando-se que se desenvolva uma atividade econômica predatória ilegal e que ataque os direitos fundamentais das populações tradicionais que dependem direta e indiretamente do ecossistema (QUEIROZ e BUSTAMANTE, 2020, p.3).

Avançando em sua construção, a verdadeira Bioeconomia dependerá de ações estruturantes que ampliem, consolidem e conservem o conhecimento científico sobre a biodiversidade brasileira para entender os padrões de sua distribuição geográfica e acompanhar suas mudanças ao longo do tempo. Nesta perspectiva, além de avaliar 
os interesses a serem atendidos nesta estratégia de desenvolvimento, ou seja, em vez de promover uma Bioeconomia "socialmente cega" é fundamental reconhecer $e$ valorizar as abordagens bioculturais dos povos tradicionais e comunidades locais. Assim, não surpreende que os conhecimentos tradicionais intrínsecos aos territórios oportunizem o processo de desenvolvimento de suas próprias bioeconomias e beneficiem tanto os empreendedores, quanto o tecido social, conforme afirmam (Queiroz e Bustamante, 202O).

Por fim, historicamente, a maioria dos modelos de desenvolvimento exógenos que foram adotados até hoje afetaram negativamente a Amazônia, seus povos tradicionais e suas comunidades locais, contribuindo para a expropriação de territórios indígenas e exploração indiscriminada dos recursos naturais, constituindo violações de direitos individuais e coletivos que ocorrem ao longo do processo de desenvolvimento imposto de cima para baixo e fogem do compartilhamento e implementação participativa com as comunidades envolvidas. Assim, faz-se necessário usar de maneira sábia as oportunidades de se implementar um modelo de desenvolvimento sustentável para a conservação, com base na Bioeconomia no ambiente amazônico para que não ocorra a repetição do modelo excludente e impositivo que é mero importador de tecnologias para o uso de recursos naturais regionais. (QUEIROZ e BUSTAMANTE, 2020, p.9 -11).

Para os autores (2020), é evidente a necessidade de desenvolvimento de tecnologias e capacitação de recursos humanos para a preparação de insumos em quantidade e qualidade e desenvolvimento de produtos e processos para as empresas atuantes no segmento de biocosméticos, fitoterápicos e fitofármacos.

De acordo com Willerding et al. (2020, p.10), a Bioeconomia é resultado direto da dinâmica do desenvolvimento de produtos que fazem uso de recursos da biodiversidade e que podem ser gerados a partir dos desdobramentos de diferentes áreas do conhecimento, incluindo ciências básicas (biologia molecular, microbiologia, biologia celular, genética, genômica, embriologia etc.), ciências aplicadas (técnicas imunológicas, químicas e bioquímicas etc.) e áreas tecnológicas (informática, robótica e controle de processos).

Para Abrantes (2006, p.34), o uso econômico dos produtos naturais amazônicos deverá ser o ponto de partida para a inserção econômica da região na matriz de um novo modelo de desenvolvimento local. Porém, o Estado do Amazonas bem como os demais estados da Amazônia ainda não dispõe de tecnologias capazes de serem alocadas para a valorização dos recursos naturais, o que se tem atualmente é uma vasta quantidade de atividades econômicas desconectadas com pouco ou quase nenhum valor agregado.

A principal estratégia do Estado do Amazonas para o fortalecimento da Bioeconomia é o conhecimento, formação do capital humano (através do fortalecimento e ampliação de recursos) e a infraestrutura laboratorial para perseguir linhas de pesquisas avançadas relacionadas à biologia sintética, genômica, proteômica e de biomateriais (WILLERDING et al. 2020).

Para Willerding et al. (2020), a estratégia estadual tem como objetivo gerar uma massa crítica de pesquisadores qualificados e lideranças científico-tecnológicas, que facilitarão a articulação com instituições internacionais de alto renome, de modo que esses grupos também se tornem referência na fronteira da Bioeconomia, uma vez que este novo modelo demanda por pesquisador-empreendedor-inovador, da formação de grupos científicos multidisciplinares capazes de se relacionar eficaz e eficientemente com o mundo empresarial, segue a linha de pensamento da CNI (2014, p.14), "é preciso remover as barreiras de transferência do conhecimento científico-tecnológico do 
ambiente acadêmico para o ambiente empresarial e ampliar o conhecimento sobre estratégias de proteção, comercialização e gestão de bens de propriedade intelectual".

Ainda sobre o Estado do Amazonas, a Bioeconomia é sem dúvida um novo vetor potencial para o desenvolvimento que se vem somar às características econômicas estaduais. Porém, para que este movimento seja próspero torna-se imprescindível a regularização deste através de políticas públicas que incluam atividades habilitadoras necessárias para a construção de uma estratégia colaborativa, por exemplo, a bioprospecção de novas moléculas de interesse biotecnológico, a formação de programas de pesquisa, desenvolvimento e inovação de bioconversão, bem como a química fina, marco regulatório, infraestrutura, comunicação e capacidade de impulsionar uma base de cientistas e tecnologia, empreendedores e inovadores, de forma a garantir e consolidar a Bioeconomia no Estado. (WILLERDING et al. 2020 apud BASECAMP, 2017).

Segundo informações da Seplancti (2017), a qual realizou um mapeamento das instituições de ensino em todo o Estado do Amazonas, conforme podemos observar na Figura 1, e concluiu que o estado apresenta uma situação considerada favorável se comparada aos demais estados da região amazônica pois a presença das instituições de ensino no interior atende à qualquer expectativa de planejamento. Contudo, necessitamos direcionar o nicho de formação para atender ao modelo desenvolvimentista da Bioeconomia e influenciar positivamente a economia dos municípios do interior do estado aproveitando a presença das instituições já instaladas e transformando-as em centros ou polos de desenvolvimento regional com foco na geração de emprego e novas oportunidades.

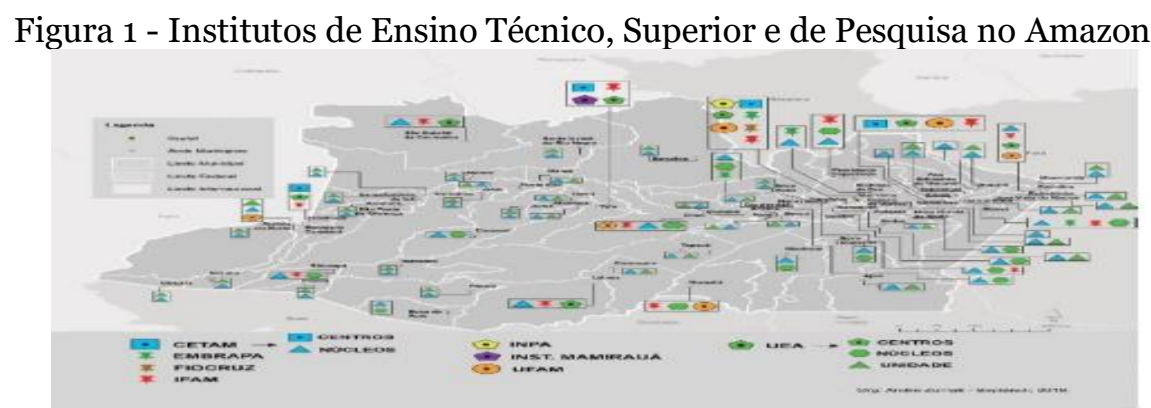

Fonte: Seplancti (2017).

Como podemos observar na Figura, o Amazonas já dispõe de uma infraestrutura educacional (UFAM, UEA, IFAM, CETAM, Sistema S, entre outros) que pode e deve ser aproveitada para a implementação e fortalecimento do Eixo da Bioeconomia com o propósito de interiorização da atividade econômica visto que temos a presença deste centro de referência na formação profissional em quase todos os municípios do interior do estado e estes apresentam elevado potencial para serem transformados em polos de conhecimento de capital humano possibilitando a geração de emprego e novas oportunidades. 


\section{BIOPRODUTOS AMAZÔNICOS E SUAS POTENCIALIDADES}

Dada a rica biodiversidade dos produtos oriundos da floresta amazônica, observa-se uma discrepância entre alguns bioprodutos mais evoluídos com relação ao nível e conhecimento ou de capacitação, tais como: a castanha-do-brasil e do açaí. Ao mesmo tempo, o camu-camu, extremamente rico com vitamina $\mathrm{C}$, apresenta seus níveis nos segmentos analisados bem baixos ou mesmo nulos. Isso, por outro lado, mostra o potencial e o campo ainda aberto que essa cultura tem para ser explorada tanto no aspecto da ciência básica como no desenvolvimento tecnológico de produtos. (WILLERDING et al. 2020).

Figura 2 - Nível de conhecimento, capacitação, tecnificação e de afinidade com o mercado para alguns bioprodutos estratégicos (AM)

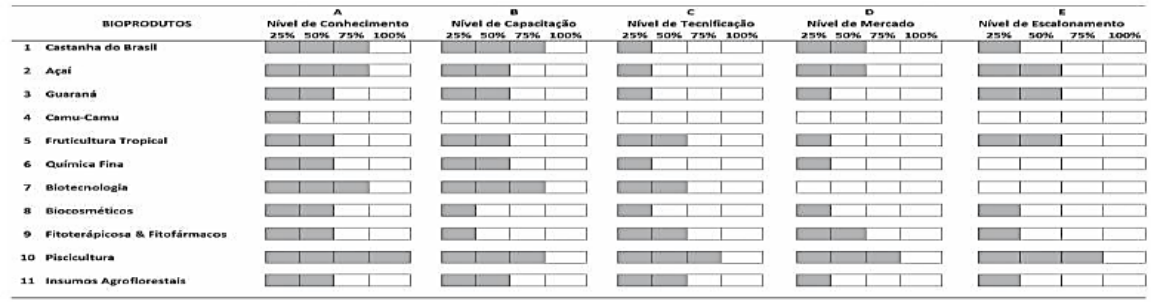

Fonte: Willerding et al. (2020) apud Seplancti (2017).

Com destaque para a castanha do brasil, açaí, guaraná, camu-camu, fruticultura tropical, química fina, biotecnologia, biocosméticos, fitoterápico \& fitofármacos, piscicultura e insumos agroflorestais. De acordo com a Figura 2, dos bioprodutos apresentados muito se necessita melhorar no que tange aos níveis de capacitação, tecnificação, mercado e escalonamento para que assim possamos iniciar o processo do potencial bioeconômico estadual.

\section{STARTUPS DA FLORESTA E O IMPULSO PARA A BIOECONOMIA}

De acordo com Silva e Girardi (2020), o universo de startups em gestação na Amazônia com foco em atividades sustentáveis pode ser considerado um exemplo para fomentar a Bioeconomia que governos, grupos empresariais, investidores e ambientalistas buscam para desenvolver a região e gerar renda para a população local sem a necessidade de derrubar ou queimar a floresta. Tais iniciativas são baseadas em atividade fomentadas através de projetos locais, que vão desde a exploração do açaí à cosméticos e tem como foco pequenos negócios inovadores com elevado potencial para transformar o cenário regional.

Ainda para as autoras (2020), o caminho trilhado pelas startups amazônicas baseadas na Bioeconomia envolve comunidades ribeirinhas, indígenas, quilombolas e agricultores familiares. A lógica está na associação da ciência com a tecnologia com foco na exploração de ativos regionais desde o início da cadeia produtiva com o objetivo de aumentar o valor agregado dos produtos, beneficiar as populações locais e impulsionar a economia regional.

Levando-se em consideração que o Brasil detém a maior biodiversidade vegetal do mundo (50 mil espécies de plantas, sendo 20 mil endémicas - que ocorrem somente no País), ressaltamos que todos os biomas nacionais apresentam potencialidades para o desenvolvimento de uma economia baseada na biodiversidade, mas é a região 
amazônica a que oferece as mais relevantes condições para investimentos imediatos (SILVA e GIRARDI, 2020).

Segundo informação do Instituto WRI Brasil (2020), com base nos dados do Censo Agropecuário do IBGE, 74\% das atividades extrativistas não exaustivas (a partir de sementes, folhas, óleos, sem a derrubada da árvore) estão na Amazônia.

De acordo com o Instituto de Conservação e Desenvolvimento Sustentável da Amazônia (Idesam) ainda não há dados precisos sobre o número exato de startups da floresta, mas em duas chamadas realizadas via Programa de Aceleração de Negócios de Impacto promovido pela Plataforma Parceiros pela Amazônia (PPA) foram inscritos 280 projetos, no ano de 2020.

Segundo informações do Idesam (2020), o instituto captou R \$ 6 milhões neste período e selecionou 30 empreendedores para participarem de cursos de capacitação, monitorias e oficinas sobre como conciliar o desenvolvimento econômico e conservação da Amazônia, tais ações foram possíveis levando-se em consideração investimentos híbridos.

\section{ECONOMIA DO CONHECIMENTO DA NATUREZA}

De acordo com Abramovay (2019), a proposta de implementação de um modelo de desenvolvimento regional baseado na exploração da Bioeconomia possibilitará a redução das emissões de gases de efeito estufa uma vez que contribuirá para reduzir o desmatamento e abrirá caminho para uma economia baseada no conhecimento da natureza.

Ainda para o autor (2019), para se implementar o modelo econômico baseado no conhecimento da natureza e transformar a vasta riqueza da biodiversidade amazônica em fonte de desenvolvimento precisamos estabelecer três questões básicas, sendo: evitar a destruição da área que concentra a maior biodiversidade do planeta, reconhecer o papel das populações tradicionais e suas atividades de ocupação e por fim fortalecer a transição de uma economia da destruição da natureza para uma economia do conhecimento da natureza.

Abramovay (2019) apud Nobre et al. (2016), chama a atenção para a urgência de que os dispositivos da chamada $4^{\mathrm{a}}$ Revolução Industrial sejam aplicados ao conhecimento e à própria exploração da Amazônia. Trata-se do Projeto Amazônia 4.0 que envolve também o monitoramento de microorganismos em laboratórios locais para a capacitação do capital humano regional com foco nos negócios sustentáveis, como veremos a seguir.

\section{O MODELO DE BIOINDUSTRIALIZAÇÃO DA AMAZÔNIA}

O Brasil bem como a Amazônia dispõe de relevante potencialidade para se tornarem protagonistas de um modelo de desenvolvimento bioeconômico endógeno baseado nos recursos tecnológicos da revolução 4.o e na biodiversidade da floresta, algo inédito para os países de clima tropical. Uma vez que a Amazônia oferece uma vasta biodiversidade, que constitui uma Terceira Via, e esta ao se juntar com a revolução digital e a revolução de nanomaterial tem o poder de potencializar este novo modelo desenvolvimentista. (NOBRE, 2019, p.1).

Para Nobre (2019), a denominada Terceira Via surge como "uma bioeconomia de floresta em pé, com sistemas florestais, numa escala reduzida e com exploração sustentável através de ferramentas do século XXI, da $4^{\mathrm{a}}$ Revolução Industrial. 
Ademais, o grande potencial para o século XXI é a utilização e o conhecimento sustentável da biodiversidade com o olhar para as tecnologias e a utilização dos ativos biológicos da floresta, de forma a promover o uso de produtos florestais com o objetivo de fomentar uma nova economia regional uma vez que o modelo de extração sustentável dos produtos agroflorestais se apresenta mais lucrativo que o modelo tradicional que elimina a floresta (Nobre, 2020).

Segundo Nobre (2019), depois de duas décadas de desindustrialização, o Brasil precisa investir numa "industrialização acelerada" para que possa se tornar um país mais competitivo, e a base desse processo são as tecnologias da $4^{a}$ Revolução Industrial. Com o investimento bioeconômico, poderíamos levar desenvolvimento para a região amazônica o que possibilitaria aumentar a renda total regional $e$ contribuiria para reduzir drasticamente a desigualdade socioeconômica, uma vez que parte significativa da renda seria apropriada pelas populações amazônicas. Essas populações, por sua vez, agregariam valor aos seus produtos, seria possível desenvolver milhares de pequenas bioindústrias, possibilitaríamos a criação de inúmeros empregos de classe média (industriais) e tudo isso possibilitaria uma conexão entre a economia local, regional, nacional e internacional o que constitui a base do modelo de bioindustrialização da Amazônia, ora proposto.

\section{PERCURSO METODOLÓGICO}

Neste item, relata-se o percurso metodológico usado para atingir os objetivos estabelecidos, que são de analisar a Bioeconomia como alternativa complementar frente ao atual modelo de desenvolvimento aproveitando as potencialidades regionais e a rica biodiversidade através de Parcerias Público-Privada. Para atingir tal propósito, utilizou-se a pesquisa bibliográfica como meio de investigação, a partir de fontes secundárias, de publicações impressas ou disponíveis na Internet.

Este artigo é parte de uma pesquisa mais ampla que tem por objetivo analisar cada uma das alternativas discutidas regionalmente (Bioeconomia, Piscicultura, Polo de Transformação Digital e Ecoturismo) para complementar o atual modelo de desenvolvimento regional estadual.

Além do conhecimento acerca das alternativas complementares ao modelo de desenvolvimento regional vigente existe um interesse em levar a discussão para os grupos de trabalho à nível estadual e local para o melhor aproveitamento da informação e do conhecimento acerca das potencialidades.

Para tanto, fez-se uso da pesquisa de natureza qualitativa e, a partir dessa base teórica, optou-se por apoiar-se também na pesquisa do tipo descritiva e explicativa, que tem como função principal a análise do objeto, buscando descrever o estado da arte nos temas escolhidos e identificar as causas dos fenômenos estudados, sendo eles: Os Modelos de Desenvolvimento Regional do Amazonas: O Ciclo da Borracha e a ZFM; Fragilidades do Modelo ZFM: Legado Social e Ambiental; A Bioeconomia como Proposta de Modelo de Desenvolvimento Regional Endógeno; Bioprodutos Amazônicos e suas Potencialidades; Startups da Floresta e o Impulso para a Bioeconomia; Economia do Conhecimento da Natureza e O Modelo de Bioindustrialização da Amazônia. As pesquisas descritivas e explicativas, de acordo com Mattar (1993) e Vergara (1999), servem para descobrir e observar fenômenos, procurando descrevê-los, classificá-los, analisá-los bem como interpretá-los. 


\section{RESULTADOS E CONCLUSÕES}

Com o objetivo de analisar a Bioeconomia como alternativa complementar frente ao atual modelo de desenvolvimento aproveitando as potencialidades regionais e a rica biodiversidade através de Parcerias Público-Privada, iniciamos nossa análise com um breve histórico do ciclo econômico da Monocultura da Borracha e aspectos referentes ao Modelo Zona Franca de Manaus (ZFM).

Dada a fragilidade e a imperfeição do atual modelo que gera concentração de renda e riqueza, vulnerabilidade social e não foi capaz de suprir as necessidades básicas infraestruturais (água tratada, esgotamento sanitário, etc..) além de negligenciar a riqueza para os demais municípios do interior inclusive para os que compõem a RMM apontamos a Bioeconomia como uma alterativa complementar viável uma vez que podemos aproveitar a biodiversidade amazônica, a infraestrutura educacional já cristalizada no interior, o conhecimento da floresta bem como gerar emprego e renda para a população regional tendo como base a preservação ambiental.

Devemos buscar alternativas para reduzir as discrepâncias em relação aos níveis de conhecimento e capacitação dos bioprodutos (a castanha do brasil, açaí, guaraná, camu-camu, fruticultura tropical, química fina, biotecnologia, biocosméticos, fitoterápico \& fitofármacos, piscicultura e insumos agroflorestais) para que possamos explorá-los bioeconomicamente além de implementar ações conjuntas para acelerar a descoberta e exploração de novos bioprodutos dada a riqueza da biodiversidade amazônica.

Ademais, incentivar e fomentar ainda mais a instalação de startups da floresta que tenham como foco atividades inovadoras e possibilitem o aproveitamento de conhecimento regional, a participação do setor público, do setor privado, de empresário, de investidores, de instituições de ensino e pesquisa, de inovação bem como de ambientalistas para fomentar negócios locais inovadores com o objetivo de gerar emprego e renda e qualificar o capital humano regional.

Buscar o fortalecimento de um novo olhar para a economia de forma a aproveitar o conhecimento da natureza pelas populações tradicionais e a necessidade de se agregar valor aos produtos oriundos da biodiversidade. Assim, contribuiremos para a redução do desmatamento e consequentemente das emissões dos gases de efeito estufa e possibilitando uma transição de uma economia da destruição da natureza para uma economia do conhecimento da natureza.

Acompanhar o amadurecimento da proposta de implementação do modelo de bioindustrialização na Amazônia que leva em consideração a biodiversidade e os recursos tecnológicos da revolução 4.0 com foco no desenvolvimento bioeconômico endógeno que ora somado aos conhecimentos da revolução digital e da revolução de nanomateriais pode ser considerado uma Terceira Via uma vez que está baseado na exploração da floresta em pé e de sistemas florestais numa escala reduzida com foco na exploração sustentável.

Acreditamos que a Bioeconomia pode ser utilizada como modelo desenvolvimentista tanto para o Estado do Amazonas como para os demais estados da Amazônia de forma a vislumbrar um futuro promissor, com foco na articulação local, regional, nacional e internacional que promova parcerias entre o setor público e a iniciativa privada com o objetivo de impulsionar e intensificar os fluxos comerciais e financeiros, conhecimento, capital humano, tecnologia, empreendedorismo e gerar oportunidades de novos negócios.

Porém, como foi possível observar ao longo deste texto, nenhuma empresa, universidade ou agência governamental pode enfrentar esse desafio de forma isolada, 
necessitamos da colaboração dos stakeholders e é por esse motivo que se faz necessária a implementação de estratégias bem claras, seleção de prioridades, colaboração e execução de tarefas focadas.

Por fim, defendemos que esse novo e badalado modelo econômico complementar baseado na Bioeconomia, deve seguir a linha de uma política pública industrial, alinhando o crescimento econômico, a preservação ambiental, aproveitando os conhecimentos da floresta, a tecnologia, a ciência e a inovação contribuindo para reduzir as vulnerabilidades socioeconômicas ambientais regionais.

\section{REFERÊNCIAS}

ABRAMOVAY, R. Amazônia por uma Economia do Conhecimento da Natureza. - São Paulo: Edições Terceira Via; Abong; Iser Assessoria: 2019. 122 p.

ABRANTES, J. S. Bio(sócio)diversidade e empreendedorismo ambiental na Amazônia. Rio de Janeiro: Garamond, 2006. 230p.

ARAÚJO, J. J. C. do N. PAULA, E. A. de. Novas formas de desenvolvimento do Amazonas: Uma leitura as ações do Programa Zona Franca Verde. 2009. Disponível em: http://www.rbgdr.net. Acesso em: 26 de março de 2020.

BASECAMP CONSULTORIA. Strategic Roadmap for the Brazilian Bioeconomy. São Paulo: Natura, Givaudan e Kimberly-Clark, 2017. 26p.

CARVALHO, A. L. de. Amazônia: Modelos de Desenvolvimento e a Questão Zona Franca de Manaus. Geografia em Questão. V. o8, n. 02, 2015. (p. 109-128). Disponível em: http://revista.unioeste.br. Acesso em: 31 de março de 2020.

CARVALHO, T. S.; DOMINGUES, E. P. Projeção de um cenário econômico e de desmatamento para a Amazônia Legal brasileira entre 2006 e 2030. Nova Economia, 26(2), 585-621, 2016.

CNI. Confederação Nacional da Indústria. Bioeconomia: oportunidades, obstáculos e agenda. Brasília: CNI, 2014. 81p.

COMISSÃO EUROPEIA. Communication from the Commission to the European Parliament, the Council, the European Economic and Social Committee and the Committee of the Regions. Strategy for "Innovating for sustainable grow: a bioeconomy for Europe”. Bruxelas, 2012. Disponível em: <http://ec.europa.eu. Acesso em: 26 de março de 2020.

COSTA, A. B.; BIDERMAN, C. A dinâmica da concentração do emprego industrial no Brasil (1991-2011) e o ciclo de vida das empresas. Anais do XLII Encontro Nacional de Economia (ANPEC), 2014.

FIESP. O Que é Bioeconomia. 2019. Disponível em: https://www.fiesp.com.br. Acesso em: 26 de março de 2020.

GALINARI, R.; CROCCO, M. A.; LEMOS, M. B.; BASQUES, M. F. D. O efeito das economias de aglomeração sobre os salários industriais: uma aplicação ao caso brasileiro. Revista Economia Contemporânea, 11(3), 391-420, 2007. 
GEORGESCU-ROEGEN, N. The entropy law and the economic process. Cambridge, MA: Harvard University Press, 1971.

GOVERNO FEDERAL. MCTI. 2019. Bioeconomia: Diversidade e Riqueza para o Desenvolvimento Sustentável. Disponível em: https://snct.mctic.gov.br. Acesso em: 26 de outubro de 2020.

HOLLAND, M. et.al. Zona Franca de Manaus: Impactos, Efetividade e Oportunidades. FGV, disponível em: http://site.suframa.gov.br. Acesso em: 11 de abril de 2020.

IBGE. Instituto Brasileiro de Geografia e Estatística. Estatísticas do Estado do Amazonas. Disponível em: https:// https://www.ibge.gov.br. Acesso em: 30 de março de 2020.

INSTITUTO ESCOLHAS. Uma Nova Economia para o Amazonas: Zona Franca de Manaus e Bioeconomia. São Paulo, 2019. Disponível em: http://www.escolhas.org. Acesso em: 10 de janeiro de 2020.

INSTITUTO WRI BRASIL. Uma Nova Economia para um Nova Era: Elementos para a Construção de uma Economia mais Eficiente e Resiliente para o Brasil. Disponível em: https://wribrasil.org.br/pt/publicacoes/nova-economia-brasil-eficiente-resilienteretomada-verde. Acesso em: 25 de dezembro de 2020.

INSTITUTO DE CONSERVAÇÃO E DESENVOLVIMENTO SUSTENTÁVEL DA AMAZÔNIA (Idesam). Programa de Aceleração da PPA divulga negócios selecionados para a turma de 2020. Disponível em: http://www.idesam.org. Acesso em: 25 de dezembro de 2020.

IPEA. INSTITUTO DE PESQUISA ECONÔMICA APLICADA. Brasil 2035: cenários para o desenvolvimento. Brasília, 2017.

JOLY, C. NOBRE, C. A Preservação da Amazônia através da Bioeconomia. 2020. Academia Brasileira de Ciências. Disponível em: http://www.abc.org.br. Acesso em: 20 de outubro de 2020.

MATTAR, F. Pesquisa de Marketing: Metodologia, Planejamento. 5. ed. São Paulo: Atlas, 1993.

McCORMICK, K.; KAUTTO, N. The Bioeconomy in Europe: an overview. Sustainability, v. 5, n. 6, p. 2.589-2.608, 2013.

MIRANDA, R. N. de. Zona Franca de Manaus: Desafios e vulnerabilidades. Senado Federal, Núcleo de Estudos e Pesquisas, texto para discussão $\mathrm{n}^{0}$ 126, abril/2013, disponível em: http://e-revista.unioeste.br. Acesso em: 20 de outubro de 2020.

NOBRE, C. Amazônia, Possível Laboratório da Bioeconomia. Outras Mídias. 2019. Disponível em: https://outraspalavras.net. Acesso em: 20 de outubro de 2020.

NOBRE, C. et al.Land-use and climate change risks in the Amazon and the need of a novel sustainable development paradigm. PNAS, Whashington, 113 (39), pp. 10 75910 768, 27 set. 2016. Disponível em: <https://doi.org/10.1073/pnas.1605516113. Acesso em: 25 de dezembro de 2020. 
NOGUEIRA, A. C. F.; SANSON, F.; PESSOA, K. A expansão urbana e demográfica da cidade de Manaus e seus impactos ambientais. Anais XIII Simpósio Brasileiro de Sensoriamento Remoto, 2007.

PEREIRA JR, E. Dinâmicas Industriais e Urbanização no Nordeste do Brasil. Mercator - Revista de Geografia da UFC, 14(4), 63-81, 2015.

QUEIROZ, H. BUSTAMANTE, M. Os desafios para um modelo realmente sustentável e inovador de desenvolvimento da Amazônia. com ciência revista eletrônica de jornalismo científico. 2020. disponível em: https://www.comciencia.br. acesso em: 02 de novembro de 2020.

RIVAS, A.; MOTA, J. A.; MACHADO, J. A. C. (org.). Instrumentos Econômicos para a Proteção da Amazônia: a experiência do Polo Industrial de Manaus. Curitiba: Editora CRV, 2009.

SANTOS, R. História Econômica da Amazônia (1800-1920). São Paulo. T. A. Queiroz, 1980.

SEPLANCTI. Secretaria de Estado de Planejamento, Desenvolvimento, Ciência, Tecnologia e Inovação do estado do Amazonas. Relatório Técnico: Matriz Econômica Ambiental do Amazonas - Jornada de Desenvolvimento, 2017. 32p.

SILVA, L. O. da. Desenvolvimento Sustentável e a Zona Franca de Manaus. Constituição, Economia e Desenvolvimento: Revista da Academia Brasileira de Direito Constitucional. Curitiba, 2015, vol. 7, n. 13, jul-dez. p. 423-440. Disponível em: http://www.abdconst.com.br. Acesso em: 31 de março de 2020.

SILVIA, C. GIRARDI, G. Startups da Amazônia Impulsionam a Bioeconomia. Estadão: Economia e Negócios. 2020. Disponível em: http:// www.estadao.com.br. Acesso em: 25 de dezembro de 2020.

SUFRAMA. Indicadores Industriais. Disponível em: http://site.suframa.gov.br. Acesso em: 26 de março de 2020.

TEIXEIRA, L. C. A Zona Franca de Manaus: evolução e resultados. Monografia. Instituto de Economia. Universidade Federal do Rio de Janeiro, 2013.

VERGARA, S. Métodos de Pesquisa em Administração. São Paulo: Atlas, 1997.

WEINSTEIN, B. Experiência de pesquisa em uma região periférica: a Amazônia'. História, Ciências, Saúde Manguinhos, Rio de Janeiro, vol. 9(2):261-72, 2002.

WILlERDING, A. SILVA, L. SILVA, R. ASSIS, G. PAULA, E. Estratégias para o Desenvolvimento da Bioeconomia no Estado do Amazonas. Ambiente e Desenvolvimento. Estudos Avançados 34 (98), 2020. Disponível em: https://www.scielo.br. Acesso em: 03 de novembro de 2020. 
Sobre os Autores:

Michele Lins Aracaty e Silva

Email: michelearacaty@yahoo.com.br.

Marcílio Lima de Oliveira

Email: marcilio.li2@hotmail.com 